\title{
EVALUATION OF THE INFLUENCE OF THE LOGISTIC OPERATIONS RELIABILITY ON THE TOTAL COSTS OF A SUPPLY CHAIN
}

\author{
Valery Lukinskiy ${ }^{1}$, Vladislav Lukinskiy ${ }^{2}$ \\ ${ }^{1,2}$ National Research University Higher School of Economics (HSE) \\ St. Petersburg, Russia \\ ${ }^{1} P$.: 007(812)644-59-11(+61517).E-mail:lukinskiy@mail.ru \\ ${ }^{2}$ Ph.:007(812)644-59-11(+61517).E-mail:vladas27@mail.ru
}

\begin{abstract}
Nowadays in logistics integral processes between the material and related flows in supply chains are getting developed more and more. However, in spite of increasing volume of statistical data which reflect the integral processes, the influence evaluation issues of the logistic operations reliability indexes on the total logistics costs remain open and require the corresponding researches implementation.

In this article we offer the methodological approach based on the existing approaches analysis. This approach allows to evaluate the influence of the logistic operations implementation reliability on the total logistic costs constituents. At the same time, the supply chains are regarded as recoverable (reserved) systems. In the article you can see calculations examples for the supply chains with the set level of reliable work probability.
\end{abstract}

Keywords: supply chains, reliability, total logistics costs, failure models, decision making

\section{Introduction}

According to (Vasiliauskas and Jakubauskas, 2007), in order to be internationally competitive, businesses are organising strategic worldwide networks that can deliver an efficient and high-quality response to demand from any segment of the world market. The efficient and integrated organisation of such activities is often referred to as global logistics or supply chain management (SCM), and it has become the core of global competitive power.

Most experts think that nowadays we are having the fourth stage of the logistics development. To be more precise, it is the integration stage of the main (material) and related (informational, financial and others) flows in supply chains (SC). At the same time to evaluate the effectiveness of the integral SC apart from the total logistics costs (TLC) there is a tendency to use some new criteria which are able to reflect the quality and reliability of implementation of logistic operations, for instance, as a coefficient of satisfaction of demand (item fill rate) FR (Stock and Lambert, 2001) or the level of availability of products (customer service level) SL (Bowersox and Closs, 1996). According to (Palšaitis and Ponomariovas, 2012), the most important indicators (rail freight transport) for direct customers (Shippers/Consignees) are: just-in-time delivery; adapting to customer needs; access to reliable information about rates, conditions of carriage and the location of the cargo.

Sources analysis of the examined problems shows that they can be divided into two groups.

The first group is the TLC evaluation methods which are widely used, but the amount of the expenses taken into account in calculations usually makes up 4-5 (Bowersox and Closs, 1996; Stock and Lambert, 2001).

If the TLC consists only of two components and they are the ordering expenses $\mathrm{C}_{\mathrm{or}}$ and the current stocks storage costs $\mathrm{C}_{\mathrm{cs}}$, then they are used to calculate optimal (economic) order quantity (EOQ), orders number $\mathrm{N}$ for the rated period, supply frequency $\tau$ and total costs minimum $C_{\sum \min }$.

At the account of inventory management strategies, the TLC consists of 4 components because, apart from $\mathrm{C}_{\mathrm{or}} и \mathrm{C}_{\mathrm{cs}}$, the insurance stocks storage expenses $\mathrm{C}_{\mathrm{ss}}$ and deficit expenses $\mathrm{C}_{\mathrm{plc}}$ are added (Ballou, 1999; Buchan and Koenigsberg, 1963; Hadley and Whitin, 1963).

Since, the estimates $\mathrm{C}_{\mathrm{ss}}$ and $\mathrm{C}_{\mathrm{plc}}$ contain statistical characteristics, then, basically, the TLC model includes the reliability index, that is, insurance stocks availability probability.

It is important to emphasise that in this case we are speaking about one of the logistics operations, not about supply chains reliability evaluation.

The second group is the SC reliability evaluation methods. 
There are much less works that consider SC reliability evaluation issues (Blanchard, 2004; Lukinskiy et al., 2014; Kersten and Blecker, 2006). According to (Chalumuri and Yasuo, 2014), very few studies have concentrated on quantifying sources of uncertainties making travel time unreliable.

Mainly, the examined models are formed on the basis of the so-called circuit reliability (serial, parallel and mixed compound of elements with different types of redundancy). All estimates are based on the probability of faultless operation of the chain components. According to (Yatskiv et al., 2012), one of the reliability measures is the probability of no-failure, which is defined as the probability of that an object (item, system) failure does not appear during a specified period of time under stated conditions.

There are several models belonging to this group. They are logistics operation failure models, in particular, the «perfect» order model (Ballou, 1999); the model of «supply and demand» (Kersten and Blecker, 2006); the «just-in-time» model and some others (Lukinskiy V.S. and Lukinskiy V.V., 2015).

When we characterise this sources group, it is important to say that, on the one hand, the quantitative evaluation technique of reliability indicators has been formed; on the other hand, the issues of the union of the circuit reliability estimates and logistics operations (functions) failures models still remain a problem.

In conclusion it is necessary to underline that there are almost no works where we can find the indexes of TLC and the indexes of the estimation of logistic operations reliability at the same time. The only exceptions are the key performance indicators (KPI) and the SCOR-models metrics, but there we can find indexes which have been worked out with the help of the "best practices analysis", statistical data and the benchmarking. The first level metrics SCOR include "Perfect order fulfillment" (SC reliability), "Order fulfillment cycle time" (SC responsiveness) and "Supply chain management cost" (SC costs).

So, the aim of this work is to develop a new approach towards the complex assessment of the SC reliability and efficiency.

\section{Technique Development of the Reliability Influence Evaluation on the TLC}

Undertaken researching of the contiguous areas of knowledge (economics, management, marketing and other) has shown that a possible variant of an interference evaluation of the logistics operations reliability indexes on the TLC has to be based on a system approach which provides for the synthesis of the management theory models, of the reliability theory, of the economics analysis methods and other.

As a result of systematization and generalization the following methodical approach has been worked out. It includes 5 stages:

1. There has to be chosen the variant of the analysable logistic system (LS) (the existing supply chain which needs reengineering or is being designed) and the level of decision making (strategic, tactical, operating or situational).

Apparently, for the modelled chain it is possible to be limited to a simple supply chain (SSC) which includes a part of supplier's and consumer's costs.

2. In this stage one has to use the reliability calculations principles of the reserved systems (Ventsel and Ovcharov, 1983) and work out an equation to evaluate the reliable work probability of the examined SSC. As the question is about the designed system, firstly, one has to define the requirements to the faultlessness of SSC links and then one has to make the calculations for the logistics operations components.

3. For the chosen LS variant the dependence of total logistic expenses is formed. This dependence includes maximal amount of factors which reflect reliability of supply chains indexes (purchases, order, transportation, storage, inventory management, return flow and other). According to (Huber et al., 2015), logistical strategies and decisions are included in transport-related decisions by emerging total logistical costs. These costs include ordering and communication costs, inventory costs, costs for loading and unloading as well as general transport costs. Furthermore, total logistics costs are influenced by goods' characteristics and business relationships that are crucial to distribution and transport deals between actors.

4. The model of failure of logistic operations in supply chains (Gertsbakh and Kordonsky, 1966; Lukinskiy V.S. and Lukinskiy V.V., 2015) is taken to calculate probabilistic descriptions which allow to estimate the level of influence of reliability indexes on expenses elements of a TLC model (e.g. probability of perfect order fulfilment or delivery "just in time").

Here we have to examine 2 variants: the first one is to minimise TLC if there are any limitations of reliability indexes; the second one is to maximise the operations reliability indexes with the TLC amount limitations. 
5. Analysing the obtained calculation TLC values and decision making about the probable changing of the probabilistic indexes of logistics operations if their values will exceed set (chosen) normative values.

In this case you are supposed to re-examine the complex of factors, that is, you have to return to the point 2 of this algorithm.

\section{Calculation of Logistics Operations Reliability Indexes}

According to the worked out method let us choose the reliability indexes calculation variant for the designed SC. A fundamental distinction from the other variants (reengineering or existent SC) is that limited information volume can be used for a calculation in this case, because there is data collection possibility about the real object functioning. Additional limitation is taken to the fact that the SC is seen large-sized at the level of the aggregated operations. For example, instead of the process specification including loading, transportation and unloading only one logistic operation (transportation) is included into a calculation chart.

The first stage. Let us assume that the SSC, on the basis of that the multilevel logistic systems are formed, consists of three operations, each of these is characterized by a probability of faultless work of $\mathrm{P}_{\mathrm{i}}$ : order forming at a supplier warehouse $-\mathrm{P}_{1}$; transportation (from a supplier to the consumer) - $\mathrm{P}_{2}$; order receiving and control at a consumer warehouse $-\mathrm{P}_{3}$.

We consider that for each of the indicated operations in the SC there are reserve components (insurance stocks, goods substitute, alternative variant of service implementation etc.) that, in fact, convert the examined SC into the recoverable system (Fig. 1). According to (Mazurkiewicz and Walkowiak, 2013), the system is designed to work at a given level of availability by including some redundancy to system resources (mainly trucks and drivers) in case of unpredictable and rare situations like shortage of drivers (for example, due to some contagious diseases or a strike). The only solution to such critical situation is to enlarge system resources, i.e., hire more drivers and trucks for a short time. The question is how many additional resources should be added to the system to eliminate the critical situation and for how long time.

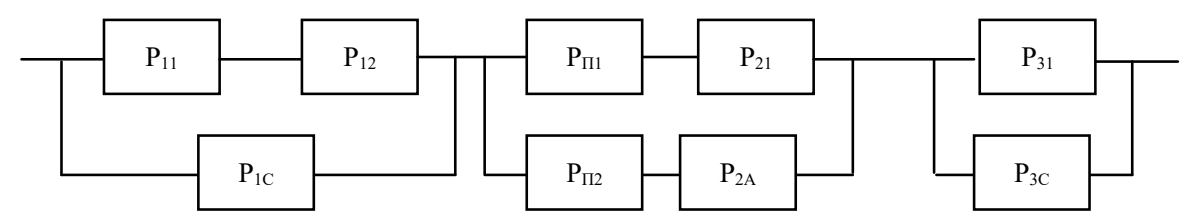

Figure 1. Calculation chart for the designed SSC reliability evaluation

In Fig. 1 faultlessness probabilities of following calculation chart components are shown:

$\mathrm{P}_{11}, \mathrm{P}_{12}$ are quantitative and qualitative perfect order evaluations;

$\mathrm{P}_{1 \mathrm{C}}$ is the supplier's insurance stocks (for the perfect order picking);

$\mathrm{P}_{21}, \mathrm{P}_{2 \mathrm{~A}}$ are main and alternative transportation variants accordingly;

$\mathrm{P}_{31}, \mathrm{P}_{3 \mathrm{C}}$ are evaluations of received order at a consumer's warehouse and insurance stocks accordingly;

$\mathrm{P}_{\Pi 1}, \mathrm{P}_{\Pi 2}$ are logical switches.

The role of logical switch is reduced to the fact that using the basic route $P_{\Pi 1}=1$, and $P_{\Pi 2}=0$; and using the alternative route $\mathrm{P}_{\Pi 1}=0$, and $\mathrm{P}_{\Pi 2}=1$.

General equation for SSC faultless work probability as a system with as serial components connection is written down in a following way:

$P_{\Sigma}=\sum_{i=1}^{n} P_{i}=P_{1} \cdot P_{2} \cdot P_{3}$

At the substitution of Pi values taking into account the reservation components (Fig. 1) in equation (1) we will get:

$P_{\Sigma}=\left[1-\left(1-P_{11} \cdot P_{12}\right)\left(1-P_{1 C}\right)\right] \cdot\left[1-\left(1-P_{\Pi 1} \cdot P_{21}\right)\left(1-P_{\Pi 2} \cdot P_{2 A}\right)\right] \cdot$

$\cdot\left[1-\left(1-P_{31}\right)\left(1-P_{3 C}\right)\right]$ 
The dependences analysis shows that some $\mathrm{P}_{\mathrm{ij}}$ faultless work probabilities are normative (or set) at the stage of designing, for example, $\mathrm{P}_{11}$ and $\mathrm{P}_{12}$; the others, in particular, $\mathrm{P}_{1 \mathrm{C}}, \mathrm{P}_{2 \mathrm{~A}}$ and $\mathrm{P}_{3 \mathrm{C}}$, must be examined considering the limitations applied for the whole system.

Let $P_{\Sigma}$ be such limitation, and probabilities of $\mathrm{P}_{\mathrm{i}}$ are equal $\mathrm{P}$. Then applying to the three examined subsystems it is possible to write down:

$P=\sqrt[n]{P_{\Sigma}}$

It allows to get calculation dependences for every reservation component. For example, for a supplier's warehouse we have:

$P=\sqrt[n]{P_{\Sigma}}=1-\left(1-P_{11} \cdot P_{12}\right)(1-Y)$,

where $\mathrm{Y}$ is the sought faultlessness probability (deficit absence) at a supplier's warehouse.

From equation (4) we find:

$Y=P_{1 C}=\left(\sqrt[n]{P_{\Sigma}}-P_{11} \cdot P_{12}\right) /\left(1-P_{11} \cdot P_{12}\right)$

Apparently, those analogical dependences can be used for the calculation of $\mathrm{P}_{3 \mathrm{C}}$.

The second stage. Analysis of numerous researches has allowed us to create a TLC model as follows (for the normal distribution laws of random variables):

$C_{\Sigma}=\frac{A \cdot C_{0}}{Q}+\frac{A \cdot C_{t}}{Q}+\frac{Q}{2} \cdot C_{p s} \cdot f+C_{p s} \cdot f^{*} \cdot \sigma_{s} \cdot x_{p}+\frac{A}{Q} \cdot \sum_{j=1}^{n} C_{p l_{-j}} \cdot \sigma_{s} \cdot I\left(x_{p}\right)_{j}$,

where, $\mathrm{C}_{\mathrm{ps}}$ is the price from the supplier per unit in conventional units (c.u.), A represents the consumption (products) in units, $\mathrm{C}_{\mathrm{o}}$ is ordering costs (where the expenses of order process and goods picking at the warehouse are included) in c.u., $\mathrm{Q}$ is shipment size in units, $\mathrm{C}_{\mathrm{t}}$ is transportation costs in c.u., $\mathrm{f}$ is storage costs of the current stock, in total price of products (share), $\mathrm{f}^{*}$ is storage costs of an insurance stock, in total price of products (share), $\sigma_{\mathrm{s}}$ is standard deviation of stock in units, $\mathrm{x}_{\mathrm{p}}$ is the ratio of the normal law of distribution (Math), $\mathrm{j}$ - the type of violation (e.g. delay, lack of documents, wrong order picking and so on.), $\mathrm{n}$ - the violations types amount, $\mathrm{I}\left(\mathrm{x}_{\mathrm{p}}\right)_{\mathrm{i}}$ is the integral of losses which characterises the mean size of the violation; $\mathrm{C}_{p_{l_{j}}}$ is the penalty in c.u. (fine size for the $\mathrm{j}$-th violation kind).

The registration of the $\mathrm{j}$-th expenses (fines) kind connected with the failures in supply chains or shortage, or delay at the order picking at the warehouse or transportation is done using the so-called integral of losses (Axsäter, 2006) and that is the peculiarity of the equation (6)

$I(x)=\int_{x}^{\infty}(t-x) \varphi(t) d t=\varphi(x)-x(1-\Phi(x))$,

where $\varphi(x), \Phi(x)$ are accordingly the density and function of random variables distribution of $\mathrm{x}$.

To calculate the value of $C_{\Sigma}$ it is necessary to obtain the dependences of the costs and expenses (fines) from the SSC logistics operations reliability indexes.

The calculation peculiarity by the (6) formula is that the insurance stocks storage costs are considered both at the supplier's warehouse and at the consumer's one.

The third stage implies the logistics operations indexes calculation which will help to make reservation (insurance stocks, alternative variants of service operations, service activities and others), for example (Lukinskiy V.S. and Lukinskiy V.V., 2015).

Calculation of insurance stocks size at a supplier's warehouse. Let us assume that to describe a perfect order it is possible to use the binomial distribution. It means that probability of complete picking of every order will make $P=P_{11} \cdot P_{12}$, according to incomplete supply $q=1-P$. It is known that at certain terms the binomial distribution aspires to normal. Then, at a known $\mathrm{P}_{1 \mathrm{C}}$ (formula (5), we find $\mathrm{x}_{\mathrm{p}}$ and calculate an insurance stock (for a perfect order picking): 
$Q_{S S}=q \cdot Q_{E O Q}+x_{p} \cdot \sqrt{Q_{E O Q} \cdot p \cdot q}$,

where $\mathrm{Q}_{\mathrm{EOQ}}$ is an economic order quantity.

On the $\mathrm{Q}_{\mathrm{ss}}$ basis we calculate the costs included in the total costs equation.

Transportation. According to (Krüger and Vierth, 2015), different factors that can cause unreliable transports: organisational (i.e. not available vehicle), human (i. e. accidents caused by tired drivers), stochastic (i.e. extreme weather) and infrastructure related (i.e. overloaded roads).

When one evaluates the transport-logistic operations reliability it's important to remember that it is a service, one of fundamental properties of which is warehousing impossibility. So for the choice of the main or alternative variants in calculation chart the logical switch is foreseen.

The "just-in-time" model (Lukinskiy V.S. and Lukinskiy V.V., 2015) is used to calculate the transportation indexes. According to this model the estimated delivery time (and the probability is taken into account) is defined with a formula:

$T_{J I T}=\bar{T}+x_{P} \cdot \sigma_{T}$,

where $\bar{T}, \sigma_{T}$ are the mean and standard deviation delivery time accordingly.

At preset (or chosen) parameters $\bar{T}$ and $\sigma_{T}$ let us set the $\mathrm{T}_{\mathrm{JIT}}$ time, and that will allow us to define $\mathrm{x}_{\mathrm{P}}$, and then $\mathrm{P}_{21}$, that is, the probability of JIT operations timely implementation.

Mean delay time $\overline{T_{L}}$ is determined like the calculation of middle deficit, i.e. using the losses integral.

The alternative delivery variant provides the change of parameters $\bar{T}$ and $\sigma_{T}$. The other calculations are carried out in the same way as the main variant.

In table 1 there are calculations results of the delivery probability at various $\bar{T}$ and $\sigma_{T}$. Having analysed the table 1 , we can conclude that the third alternative variant allows to satisfy the condition $\mathrm{P}_{2}>0,98$, though, the main variant can be considered as a satisfactory one.

When we calculate the transportation costs for the main variant, we take into account $\mathrm{T}_{\mathrm{JIT}}=16$ hours, when it is calculated for the alternative one, $\mathrm{T}_{\text {JIT }}$ equals 13 and 14 hours which makes the transportation cheaper, but increases the toll route segments costs.

Table 1. The evaluation variants for the 'Just-in-time' transportation implementation probability

\begin{tabular}{|c|c|c|c|c|c|c|}
\hline Variant & $\begin{array}{c}\text { Variant } \\
\text { number }\end{array}$ & $\bar{T}, \mathbf{h}$ & $\boldsymbol{\sigma}_{T}, \mathbf{h}$ & $\mathbf{T}_{\text {JIT }}$ & $\mathbf{P}_{\mathbf{2}}$ & $\boldsymbol{T}_{L}, \mathbf{m i n}$. \\
\hline Main & 1 & 12 & 2,0 & 16 & 0,977 & 1,0 \\
\hline Alternative & 1 & 10 & 1,7 & 13 & 0,964 & 1,6 \\
\cline { 2 - 7 } & 2 & 10 & 2,5 & 14 & 0,940 & 4,0 \\
\cline { 2 - 7 } & 3 & 10 & 1,7 & 14 & 0,992 & 0,3 \\
\hline
\end{tabular}

Consumer's warehouse. The indexes calculation is carried out with the formulas similar to those which have been used for the supplier's warehouse calculation. The difference is that, in addition, the definite inventary management strategy is taken into account, for example, with a fixed order size or order point ROP, and corresponding costs and expenses. It is also urgent to take into consideration that in a general case $\mathrm{P}_{31}<\mathrm{P}$ (formula (3) because while some logistic operations (storage, loading, transportation, unloading, losses, natural loss, theft) are being carried out, it becomes possible to lose a part of production.

So, the use of a developed technique lets us carry out comparative calculations of the total costs and some certain logistic operations reliability indexes.

\section{Approbation}

In table 2 there are the calculations results for the designed $\mathrm{SSC}$ with and without logistic operations reservation. For the calculations the following data has been used: $A=1200$ units; $\mathrm{C}_{0}=150$ c.u.; $\mathrm{C}_{\mathrm{t}}=500$ c.u.; $\mathrm{C}_{\mathrm{ps}}=300$ c.u.; $\mathrm{f}=0,2 ; P_{\Sigma}=0,94 ; \mathrm{P}_{11}=\mathrm{P}_{12}=0,95 ; \mathrm{P}_{21}=0,977 ; \mathrm{P}_{31}=0,95 ; \sigma_{S}=7$ units; 
$\mathrm{Q}_{\mathrm{EOQ}}=161$ units; the number of deliveries $\mathrm{N}=7$; the fine for each goods unit which hasn't been within the 'perfect' order $\mathrm{C}_{\mathrm{pl} \_1}=200$ c.u.; toll route segments costs -100 c.u. for one trip; $\mathrm{x}_{\mathrm{p}}=1,3 ; \mathrm{I}\left(\mathrm{x}_{\mathrm{p}}\right)=0,046$.

Table 2. The calculations results for the designed SSC with and without logistic operations reservation

\begin{tabular}{|c|c|c|c|c|}
\hline \multirow{2}{*}{ Logistic operation } & \multirow{2}{*}{$\begin{array}{c}\text { The model for } \\
\text { calculation }\end{array}$} & \multirow{2}{*}{ Reservation } & \multicolumn{2}{|c|}{ Costs and expenses } \\
\hline & & & without reservation & with reservation \\
\hline $\begin{array}{l}\text { Order forming at } \\
\text { the supplier's }\end{array}$ & $\begin{array}{l}\text { 'Perfect order' } \\
\text { (statistics } \\
\text { methods) }\end{array}$ & $\begin{array}{l}\text { Insurance } \\
\text { stocks }\end{array}$ & $\begin{array}{c}\text { deficit, } \\
3200 / 0,9 *\end{array}$ & $\begin{array}{c}\text { insurance stocks, } \\
1140 / 0,98^{*}\end{array}$ \\
\hline Transportation & Just-in-Time & $\begin{array}{l}\text { Alternative } \\
\text { route }\end{array}$ & $\begin{array}{c}\mathrm{T}_{\mathrm{JIT}}=16 \text { hours, } \\
4670 / 0,977 *\end{array}$ & $\begin{array}{c}\mathrm{T}_{\mathrm{JIT}}=14 \text { hours (toll road), } \\
4780 / 0,992 *\end{array}$ \\
\hline $\begin{array}{l}\text { Supply reception } \\
\text { and control }\end{array}$ & $\begin{array}{l}\text { Perfect order } \\
\text { (inventory } \\
\text { management } \\
\text { strategies) }\end{array}$ & $\begin{array}{l}\text { Insurance } \\
\text { stocks }\end{array}$ & $\begin{array}{c}\text { deficit, } \\
1600 / 0,95^{*}\end{array}$ & $\begin{array}{l}\text { insurance stocks, } \\
\qquad 540 / 0,98^{*}\end{array}$ \\
\hline \multicolumn{3}{|c|}{ Total costs (model EOQ) } & \multicolumn{2}{|c|}{9675} \\
\hline \multicolumn{3}{|c|}{ Total costs and expenses } & 20142 & 17132 \\
\hline
\end{tabular}

In spite of the conditional nature of the calculations we can say that, firstly, the account of logistic operations reliability indexes greatly influences the total costs; secondly, reliability increase (supply chain reliable work probability) can be reached either by insurance stocks increasing at the warehouses of various levels, or by using the alternative variants for some kinds of logistic operations; thirdly, in the examined example the reservation has resulted in paradoxical outcomes, that is, there is a reliable work increase for $12 \%$ and at the same time there is total costs decrease for $15 \%$ which probably is the consequence of the chosen costs indexes.

\section{Conclusion}

1. Not only does the developed technique allow to calculate the faultlessness indexes of the designed supply chains, but to evaluate total logistic costs with the reliability indexes taken into consideration, as well.

2. The carried out conditional example of the calculation proves the justice of the following hypothesis: in the view of reliability the supply chains must be regarded as recoverable (by reserving) systems. The reservation components are the insurance stocks at the warehouses of the various levels and alternative variants of logistic operations implementation.

3. It goes without saying that some positions of this methodology are debatable and require to carry out the further researches, especially from the point of view of the use of various distribution laws to describe failures, passing to the multilevel systems and etc.

\section{References}

1. Axsäter, S. (2006) Inventory control. $4^{\text {th }}$ ed. New York: Springer Science + Business Media.

2. Ballou, R.N. (1999) Business logistics Management. New Jersey: Prentice-Hill International.

3. Blanchard, B.S. (2004) Logistics Engineering and Management. $6^{\text {th }}$ ed. USA: Pearson. Prentice Hall.

4. Bowersox, D.J. and Closs, D.J. (1996) Logistical Management. The Integrated Supply Chain Process. New York: McGraw-Hill Companies, Inc.

5. Buchan, J. and Koenigsberg, E. (1963) Scientific Inventory Management. New Jersey: Prentice-Hall, Inc.

6. Chalumuri, R. and Yasuo, A. (2014) Modelling travel time distribution under various uncertainties on Hanshin expressway of Japan, Eur. Transp. Res. Rev. (2014) 6, 85-92. DOI 10.1007/s12544-0130111-3.

7. Gertsbakh, I. and Kordonsky, K. (1966) Models of failures. Soviet radio.

8. Hadley, G. and Whitin, T. (1963) Analysis of Inventory Systems. New Jersey: Prentice-Hall, Inc.

9. Huber, S., Klauenberg, J. and Thaller, C. (2015) Consideration of transport logistics hubs in freight transport demand models, Eur. Transp. Res. Rev. 7: 32. DOI 10.1007/s12544-015-0181-5. 
10. Kersten, W. and Blecker T. (2006) Managing Risks in Supply Chains. How to Build Reliable Collaboration in Logistics. Berlin: Erich Schmidt Verlag.

11. Krüger, N. and Vierth, I. (2015) Precautionary and operational costs of freight train delays: a case study of a Swedish grocery company, Eur. Transp. Res. Rev. 7: 6 DOI 10.1007/s12544-015-0155-7.

12. Lukinskiy, V.S., Lukinskiy, V.V. and Churilov, R. (2014) Problems of the supply chain reliability evaluation. Transport and Telecommunication, 15(2), 120-129. DOI 10.2478/ttj-2014-0011.

13. Lukinskiy, V.S. and Lukinskiy, V.V. (2015) Formation of failure models for the evaluation of the reliability of supply chains. Transport and Telecommunication, 16(1), 40-47. DOI 10.1515/ttj-20150005 .

14. Mazurkiewicz, J. and Walkowiak, T. (2013) Discrete transportation system's availability problem in case of critical situation sets, Transport and Telecommunication, 14(4), 272-281. DOI 10.2478/ttj2013-0023.

15. Palšaitis, R. and Ponomariovas, A. (2012) Assessment of rail freight transport service quality, Transport and Telecommunication, 13(3), 188-192. DOI 10.2478/v10244-012-0015-7.

16. Stock, J.R. and Lambert, D.M. (2001) Strategic Logistics Management. 4th ed. Boston: McGraw-Hill Irwin.

17. Vasiliauskas, A. and Jakubauskas, G. (2007) Principle and benefits of third party logistics approach when managing logistics supply chain, Transport, 22:2, 68-72 http://dx.doi.org/10.1080/16484142.2007.9638101.

18. Ventsel, E.S. and Ovcharov L.A. (1983) Applied problems of probability theory. Moscow: Radio and communications. (In Russian).

19. Yatskiv, I., Pticina, I. and Savrasovs, M. (2012) Urban public transport system's reliability estimation using microscopic simulation, Transport and Telecommunication, 13(3), 219-228. DOI 10.2478/v10244-012-0018-4. 